\title{
O IMPACTO DA LEI COMPLEMENTAR 123/2006 NAS COMPRAS PÚBLICAS: O CASO DE UM HOSPITAL UNIVERSITÁRIO
}

\author{
A. de A. MARCELINO ${ }^{1}$, P. G. M. MELO FILHO ${ }^{2}$ \\ ${ }^{1}$ Universidade Federal de Pernambuco, Centro de Ciências Sociais Aplicadas, Programa de \\ Pós-Graduação em Gestão e Economia da Saúde \\ ${ }^{2}$ Universidade Federal de Pernambuco, Centro de Ciências Sociais Aplicadas, Departamento \\ de Economia, Programa de Pós-Graduação em Gestão e Economia da Saúde \\ E-mail para contato: antoniadealcantara@hotmail.com
}

RESUMO - Os órgãos públicos realizam as contratações para atender as suas necessidades de materiais e serviços por meio de processo licitatório, o qual é regido por diversas normas. A Lei Complementar 123/2006 que visa promover o desenvolvimento das microempresas e empresas de pequeno porte alterou consideravelmente a rotina da licitação. E é neste contexto que o trabalho foi desenvolvido, objetivando avaliar os impactos da referida Lei sobre as aquisições de um Hospital Universitário. Trata-se de uma pesquisa descritiva, de natureza documental. Utilizou-se de informações referentes a licitações ocorridas no periodo de março de 2006 a fevereiro de 2017 e contratações realizadas entre julho de 2016 e junho de 2017. Os resultados demonstraram que alguns beneficios previstos na referida lei provocaram um aumento significativo dos recursos financeiros despendidos e elevaram o número de itens fracassados. Por outro lado, na fase de execução dos contratos, as empresas beneficiadas apresentaram um desempenho superior às grandes empresas. Faz-se necessário aprofundar a discussão sobre a forma adotada para promover o desenvolvimento e a robustez deste segmento empresarial, inclusive com a produção de novos estudos abrangendo órgãos de outras regiões do país e de perfis variados.

Palavras chave: Licitação, benefícios, microempresa e empresa de pequeno porte.

ABSTRACT - Public bodies perform the hiring to meet their needs for materials and services through a bidding process, which is governed by different rules. The Complementary Law 123/2006 which aims to promote the development of microenterprises and small businesses have changed considerably the routine of bidding. And it is in this context that the work was developed, aiming to evaluate the impacts of the Law on purchases of a University Hospital. This is a descriptive research, documentary nature. It was used information on the bidding process that occurred in the period from March 2006 to February 2017 and hires conducted between July 2016 and June 2017. The results showed that some of the benefits provided for in this law have led to a significant increase of the financial resources expended and increased the number of failed items. On the other hand, at the stage of the contracts implementation, the beneficiary companies exhibited 
a superior performance for large companies. It is necessary to deepen the discussion on the form adopted to promote the development and the robustness of this business segment, including the production of new studies encompassing components from other regions of the country and of different profiles.

Key words: Bidding, benefits, microenterprise and small business.

\section{INTRODUÇÃO}

As contratações efetuadas pelos órgãos públicos brasileiros submetem-se às leis de licitações vigentes no país. Uma das muitas normas que se ocupam de delinear os contornos do procedimento licitatório, a Lei Complementar (LC) 123, de 14 de dezembro de 2006, chamou-nos a atenção devido à grande interferência que exerce sobre as aquisições públicas, de maneira especial após as alterações promovidas pela Lei Complementar 147, de 7 de agosto de 2014.

A LC 123/2006 estabeleceu regras de natureza tributária, trabalhista e também de acesso ao mercado por meio de um tratamento diferenciado, simplificado e protetor visando incentivar a geração de emprego e renda. O grupo de comandos que procura estimular a participação dessas empresas nas contratações públicas alterou significativamente as fases do processo licitatório, acrescentando etapas, prazos e possivelmente repercutindo também nos preços pagos pelo poder público para atendimento de suas necessidades de materiais e serviços.

No quadro 1 encontram-se relacionados os benefícios de aplicação compulsória a serem concedidos às microempresas empresas de pequeno porte (ME/EPP) nas licitações públicas.

Quadro 1 - Benefícios previstos na LC123/2006 para as ME/EPP em licitações públicas.

\begin{tabular}{|c|c|l|c|}
\hline Benefício & $\begin{array}{c}\text { Fundamentação } \\
\text { Legal } \\
\text { (Lei 123/2006) }\end{array}$ & Descrição & Abrangência \\
\hline $\begin{array}{c}\text { Regularidade } \\
\text { fiscal e trabalhista } \\
\text { tardia }\end{array}$ & Art. 42 e 43 & $\begin{array}{l}\text { Caso exista restrição fiscal ou trabalhista, após declarada } \\
\text { vencedora, à ME/EPP será concedido o prazo de 5 dias úteis, } \\
\text { prorrogável por igual período, para regularização das } \\
\text { pendências. }\end{array}$ & Bens e serviços \\
\hline Empate ficto & Art. 45 & $\begin{array}{l}\text { Se a proposta da ME/EPP ficar até 5\% (pregão) e 10\% } \\
\text { (demais modalidades) acima da proposta vencedora, sendo } \\
\text { esta última uma grande empresa, a pequena empresa poderá } \\
\text { cobrir o valor ofertado e sagrar-se vencedora. }\end{array}$ & Bens e serviços \\
\hline $\begin{array}{c}\text { Licitação } \\
\text { exclusiva }\end{array}$ & Art. 48, Inc, I & $\begin{array}{l}\text { A Administração deverá realizar processo licitatório } \\
\text { exclusivo para ME/EPP nos itens cujo valor estimado seja de } \\
\text { até R\$80.000,00. }\end{array}$ & Bens e Serviços \\
\hline Art. 48, Inc. III & $\begin{array}{l}\text { Para os itens divisíveis cujo valor estimado supere } \\
\text { R } \$ 80.000,00,0 \text { órgão licitante deverá destinar cota de até } \\
25 \% \text { da quantidade para ME/EPP. }\end{array}$ & Bens \\
\hline
\end{tabular}

Fonte: Elaborada pela autora com informações da LC 123/2006

\section{MATERIAIS E MÉTODOS}

Trata-se de uma pesquisa descritiva enfocando os quatro aspectos citados por Marconi e Lakatos (2009, p. 6): "descrição, registro, análise e interpretação de fenômenos atuais, objetivando o seu funcionamento no presente." 
Quanto à natureza das fontes, é uma pesquisa documental, pois fez-se uso do site de compras do governo federal (Compras Governamentais), da ferramenta de gestão hospitalar (Master Tools) e dos arquivos do Hospital das Clínicas da UFPE, cujos dados ainda não sofreram tratamento analítico, por isso considerados primários. (SEVERINO, 2007)

Foi feito um levantamento das licitações abertas pelo Hospital no período de março de 2016 a fevereiro de 2017.

Verificou-se que no período considerado, o Hospital das Clínicas da Universidade Federal de Pernambuco realizou licitações apenas na modalidade pregão, na forma eletrônica, somando 109 pregões e 2.889 itens. Para mensurar o reflexo financeiro da norma para o órgão licitante, utilizou-se o índice de economicidade gerado nas disputas dos dois grupos: itens franqueados a todos os portes e itens restritos às micro e pequenas empresas, calculado pela diferença entre o valor estimado pelo órgão e o valor adjudicado. Além da economia gerada, buscou-se avaliar se as licitações proporcionaram as contratações pretendidas, calculando a taxa de êxito dos certames.

A última etapa consistiu em fazer um levantamento das contratações ocorridas no período de julho de 2016 a junho de 2017 e observar como se deu a execução contratual pelas empresas, as quais foram separadas em função da declaração de aptidão aos benefícios da Lei 123/2006 feita no processo licitatório que originou a aquisição do bem ou serviço. Buscou-se verificar se houve uma diferença significativa entre as pequenas e grandes empresas no que se refere às obrigações contratuais medida pelas notificações efetuadas pelo Hospital com relação a atraso ou não fornecimento do material ou serviço contratado, não conformidade dos produtos e serviços e a qualidade do objeto contratado.

\section{RESULTADOS E DISCUSSÃO}

Para atender o objetivo do trabalho, dois eixos foram explorados, o impacto sobre os recursos financeiros e sobre a eficiência administrativa de um hospital universitário, produzido pelas regras de acesso ao mercado, presentes na Lei Complementar 123/2006. Sendo assim, os resultados foram avaliados ao final do processo de escolha do fornecedor e durante a execução do objeto contratado.

Dos 2.889 itens licitados no período de um ano, 365 foram exclusivos para as ME/EPP e 262 foram cotas, os demais foram abertos para empresas de todos os portes.

Nos itens abertos a empresas de todos os portes o desconto médio concedido em relação ao valor estimado foi $25,56 \%$ maior que nos itens cuja participação foi restrita às pequenas empresas, conforme tabela 1. A quantidade de itens exitosos também favorece a ampla participação que obteve propostas aceitas para $69,14 \%$ de seus itens contra $57,10 \%$ dos itens restritos às empresas beneficiadas pela LC 123/2006.

Tabela 1 - Resultado das licitações realizadas no período de março de 2016 a fevereiro de 2017.

\begin{tabular}{ccc}
\hline PARTICIPAÇÃO & $\begin{array}{c}\text { DESCONTO MEDIO (em } \\
\text { relação ao valor estimado) }\end{array}$ & ITENS ACEITOS \\
\hline Ampla & $27,41 \%$ & $69,14 \%$ \\
EPP/ME & $21,83 \%$ & $57,10 \%$ \\
\hline
\end{tabular}

Fonte: Elaborada pela autora com dados do Compras Governamentais 
O gráfico 1 mostra o desfecho dos 262 itens que foram duplicados, gerando as cotas. Percebe-se que o percentual de aceitos na cota principal é $116 \%$ maior que na cota reservada, consequentemente o percentual de fracassados é de $22 \%$ contra $64 \%$, sendo que a quantidade de itens desertos, que não receberam nenhuma proposta, é bastante elevada na cota reservada às microempresas e empresas de pequeno porte.

Gráfico 1 - Desfecho dos itens com cota, licitados no período de março de 2016 a fevereiro

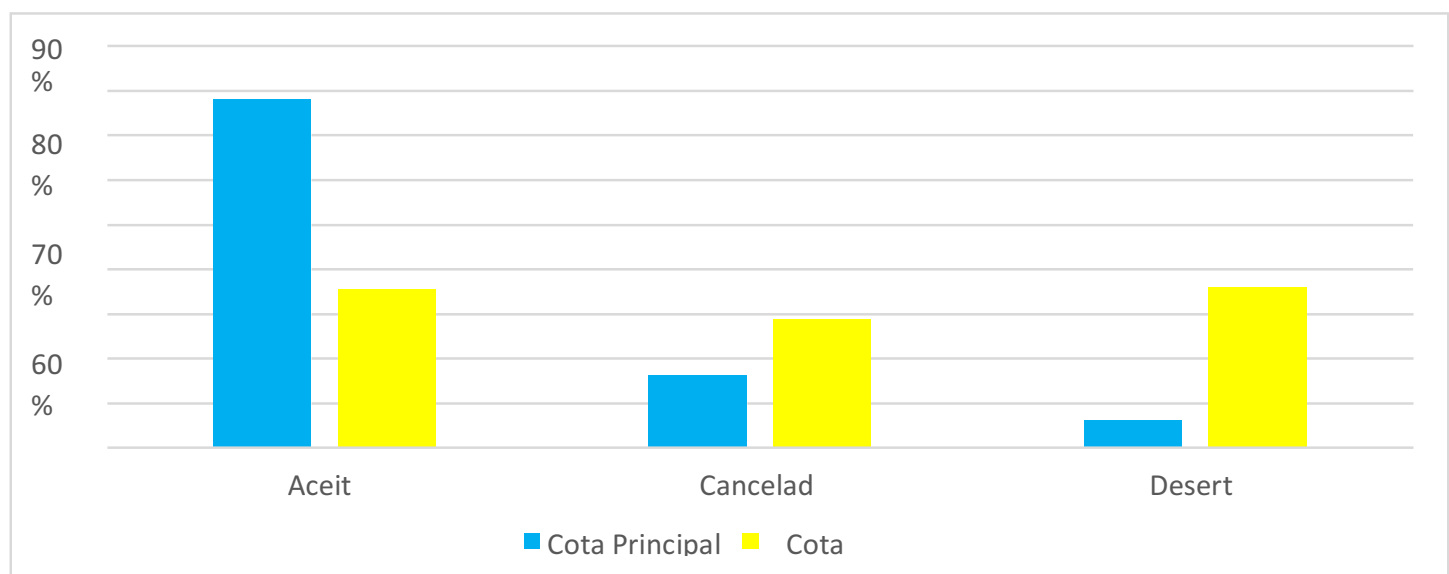

de 2017.

Fonte: Elaborada pela autora com dados do Compras Governamentais

Cotejando apenas os itens que tiveram as duas cotas aceitas, ou seja, 93 itens, a economia, calculada pela diferença entre o valor estimado e o valor adjudicado, na cota principal foi de $43,50 \%$ enquanto que na cota reservada foi menor que $30 \%$, conforme demonstrado na tabela 2. Em termos monetários houve um aumento de $\mathrm{R} \$ 355.614,75$ no custo dos mesmos materiais/produtos com a participação restrita.

Tabela 2 - Economia em relação ao valor estimado, dos itens com cota.

\begin{tabular}{ccc}
\hline GRUPO & VALOR & $\%$ \\
& ECONOMIZADO & \\
\hline Cota principal & $\mathrm{R} \$ 1.080 .825,72$ & 43,50 \\
Cota reservada & $\mathrm{R} \$ 725.210,97$ & 29,19
\end{tabular}

Fonte: Elaborada pela autora com dados do Compras Governamentais

Nota: Para efeito de cálculo, a quantidade de cada item da cota principal foi reduzida para permitir a comparação com a cota reservada.

Os resultados mostram que a licitação diferenciada responde por um aumento significativo nos preços praticados. Quando se comparou os mesmos objetos licitados com e sem restrição de porte, verificou-se que a cota exclusiva foi responsável por um aumento de $25 \%$ dos recursos financeiros necessários às contratações pretendidas, e por elevar o percentual de itens fracassados quando comparada com as licitações sem reserva de segmento empresarial. Generoso (2010) já havia identificado este incremento nas despesas, quando se restringia a competição, sendo que no órgão estudado por ele, os pregões eletrônicos exclusivos alcançaram uma economia de $14 \%$ enquanto que nos demais, a economia foi de $22 \%$.

O número de participantes é uma das explicações para a elevação dos preços dos itens limitados às ME/EPP. "A justificativa para esta relação é que quanto maior o número de 
empresas interessadas na venda do objeto em negociação, maior é o acirramento da disputa, e, assim, o órgão público consegue negócios mais lucrativos." (FARIA et al., 2010)

O porte da empresa também concorre para o preço final, devido a economia de escala obtida pelo alto volume das aquisições realizadas pelas grandes empresas, as quais gozam de maior poder de negociação. (PORTER, 1992). Como as pequenas empresas possuem uma participação mais modesta no mercado, têm mais dificuldade para reduzir os custos e apresentar valores mais baixos para os seus clientes.

A localização geográfica também exerce um papel importante na competitividade. De acordo com o Sebrae (2014) 30,7\% das ME/EPP se concentram no estado de São Paulo e somente $2,6 \%$ das empresas desse segmento econômico estão domiciliadas em Pernambuco, o mesmo estado do órgão licitante.

No aspecto relativo ao cumprimento das cláusulas contratuais, foi feito um levantamento dos empenhos emitidos durante um ano, conforme tabela 3 , tendo início no mês de julho de 2016, para refletir as contratações resultantes das licitações processadas a partir de março do mesmo ano.

Tabela 3 - Empenhos emitidos no período de julho de 2016 a junho de 2017.

\begin{tabular}{cccc}
\hline $\begin{array}{c}\text { PORTE DAS } \\
\text { EMPRESAS }\end{array}$ & $\begin{array}{c}\mathbf{N}^{\mathbf{0}} \text { DE EMPRESAS } \\
\text { CONTRATADAS }\end{array}$ & $\begin{array}{c}\mathbf{N}^{\mathbf{0}} \text { DE EMPENHOS } \\
\text { EMITIDOS }\end{array}$ & $\begin{array}{c}\text { VALOR } \\
\text { CONTRATADO }\end{array}$ \\
\hline Outros Portes & 167 & 1.533 & $\mathrm{R} \$ 29.656 .744,11$ \\
EPP/ME & 161 & 1.146 & $\mathrm{R} \$ 11.777 .320,46$ \\
\hline
\end{tabular}

Fonte: Elaborada pela autora com dados do sistema de gerenciamento hospitalar do Hospital das Clínicas de Pernambuco (HCPE)

Em seguida foi apurado o comportamento das contratadas por meio das notificações efetuadas pelo Setor de Contratos do Hospital, relacionadas a atraso e/ou desistência e também por insatisfação em relação à qualidade do produto ou serviço, a partir das reclamações dos setores usuários dos materiais e serviços. E verificou-se que na fase de execução dos contratos, as microempresas e empresas de pequeno porte têm cumprido as obrigações contratuais de forma mais satisfatória, conforme dados constantes na tabela 4 .

Tabela 4 - Notificações referentes aos empenhos originados de licitação, emitidos no período de julho de 2016 a junho de 2017.

\begin{tabular}{ccccc}
\hline PORTE & \multicolumn{2}{c}{$\begin{array}{c}\mathbf{N}^{\circ} \text { DE EMPRESAS } \\
\text { NOTIFICADAS }\end{array}$} & \multicolumn{2}{c}{$\begin{array}{c}\mathbf{N}^{\circ} \text { DE EMPENHOS COM } \\
\text { INEXECUÇÃO } \\
\text { CONTRATUAL }\end{array}$} \\
\hline Grande Porte & Quantidade & $\%$ & Quantidade & $\mathbf{\%}$ \\
ME/EPP & 39 & $23,35 \%$ & 68 & $4,44 \%$ \\
& 24 & $14,91 \%$ & 34 & $2,97 \%$ \\
\hline
\end{tabular}

Fonte: Elaborado pela autora com dados dos arquivos da Unidade de Contratos do HCPE

Não foi encontrado na literatura este enfoque, mas acredita-se que tenha relação com alguns pontos fortes das empresas de pequeno porte, como os referidos por Cândido (1998, p. 11): "arrojo, crença e obstinação pelo trabalho; agilidade nas ações e na tomada de decisões; informações internas circulam com mais facilidade; funcionários estão mais próximos dos clientes". 
A possibilidade de sofrer penalidade administrativa também funciona como um forte inibidor de inexecução contratual, particularmente pelo alto impacto que uma sanção pode causar em uma companhia com parcos recursos financeiros e muitas vezes dependentes de poucos clientes. As atuais legislações preveem desde advertência, multa, até proibição de licitar e contratar com órgãos públicos por 5 anos. Para uma empresa hipossuficiente diante da ótica econômica, uma punição mais severa pode culminar com a morte do negócio.

\section{CONCLUSÃO}

Sem desconsiderar a importância das microempresas e empresas de pequeno porte para a economia do país e das suas contribuições para o emprego, a geração de renda e a redução das desigualdades regionais, a presente dissertação se propôs a avaliar como o processo de contratação pública foi afetado pela Lei Complementar $\mathrm{n}^{\mathrm{o}} 123$, de 14 de dezembro de 2006.

Os resultados revelaram que a licitação exclusiva para itens estimados em até $\mathrm{R} \$ 80.000,00$ e a criação de cotas de até $25 \%$ do quantitativo para bens divisíveis quando superiores a $\mathrm{R} \$ 80.000,00$ tornaram o processo licitatório mais oneroso e menos eficiente, com risco de prejudicar o suprimento de bens e serviços para o funcionamento do Estado. Em vista disso, faz-se necessário aprofundar a discussão sobre a forma adotada para promover o desenvolvimento e a robustez deste segmento empresarial, inclusive com a produção de novos estudos abrangendo órgãos de outras regiões do país e de perfis variados. Aos gestores, sugere-se algumas medidas que podem minimizar os efeitos contraproducentes da opção legislativa manifestada por meio da restrição à competitividade:

Capacitar os servidores responsáveis pelas pesquisas de preços, de forma que o valor estimado retrate com fidelidade o preço praticado no mercado. Um preço de referência bem orçado impede a contratação por valor abusivo e o comprometimento além do necessário, dos finitos recursos disponíveis. Aperfeiçoar a prática fiscalizadora desde o início do processo de licitação até a execução das obrigações contratadas, de modo que as condutas reprováveis sejam punidas regularmente e de forma proporcional aos danos causados. Desenvolver, em parceria com outros órgãos que utilizam o Compras Governamentais, um sistema informatizado onde as micro e pequenas empresas possam se cadastrar informando a relação de todos os itens que fornecem, com o código do Catálogo de Materiais, e os estados onde têm interesse em participar de licitação. Seria uma ajuda preciosa para os gestores deliberarem sobre a licitação exclusiva e a cota reservada.

A regularidade fiscal e trabalhista a posteriori e o desempate ficto não se mostraram um problema significativo sobre eficiência administrativa, embora obviamente tenham estendido o tempo do processo. O primeiro amplia a concorrência possibilitando que empresas com pendências fiscais e trabalhistas possam participar do certame. E a possibilidade de cobrir o valor da primeira colocada, se esta for grande empresa e houver uma EPP/ME dentro do percentual estipulado na legislação, estimula a redução dos preços, principalmente por parte das grandes empresas. Elas estão propensas a lançarem os seus menores preços para se afastarem do intervalo que propicia o desempate. 
Outrossim, celebrar contratos com empresas menores pode ser vantajoso sob a perspectiva de cumprimento do dever contratual, pois foi observado, no caso em análise, que as mesmas conseguiram um desempenho superior.

Todavia, devido as limitações do estudo, no que concerne a metodologia, um estudo de caso, e também devido ao curto período de tempo das observações, pois é recente a aplicação de parte dos dispositivos que promove o acesso preferencial ao mercado fornecedor de bens e serviços para os poderes públicos, sugere-se novos trabalhos para verificar se os padrões encontrados se repetem. No quesito execução contratual, sabe-se que há subnotificação dos eventos adversos, o que pode ter enviesado o resultado obtido. Não obstante as suas limitações, o trabalho lançou luz sobre um aspecto pouco explorado na literatura, as consequências do tratamento diferenciado e simplificado previsto no Estatuto das Microempresas e Empresas de Pequeno Porte para os órgãos púbicos licitantes. Ademais forneceu subsídios para que alguns dispositivos da Norma sejam reavaliados de forma a harmonizar a política pública de incentivo às MPE com o pleno atendimento das necessidades da administração licitadora sem maximizar os dispêndios públicos. Pretendeu-se, também, auxiliar os gestores a mitigar os riscos inerentes às contratações.

\section{REFERÊNCIAS}

BRASIL. Lei Complementar $n^{0}$ 123, de 14 de dezembro de 2006. Institui o Estatuto Nacional da Microempresa e da Empresa de Pequeno Porte; altera dispositivos das Leis no 8.212 e 8.213, ambas de 24 de julho de 1991, da Consolidação das Leis do Trabalho - CLT, aprovada pelo Decreto-Lei no 5.452, de 1o de maio de 1943, da Lei no 10.189, de 14 de fevereiro de 2001, da Lei Complementar no 63, de 11 de janeiro de 1990; e revoga as Leis no 9.317, de 5 de dezembro de 1996, e 9.841, de 5 de outubro de 1999. Disponível em $<$ http://www.planalto.gov.br/ccivil_03/leis/LCP/Lcp123.htm>. Acesso em: 02 fev. 2017.

CÂNDIDO, Marcondes da Silva. Gestão da qualidade em pequenas empresas: uma contribuição aos modelos de implantação. Florianópolis, 1998. Dissertação (Mestrado em Engenharia de Produção), Universidade Federal de Santa Catarina. Disponível em: < https://repositorio.ufsc.br/xmlui/bitstream/handle/123456789/77455/142367.pdf?sequen $\mathrm{ce}=1$ \&isAllowed $=\mathrm{y}>$. Acesso em: 13 nov. 2017.

FARIA, Evandro Rodrigues de. et al. Fatores determinantes na variação dos preços dos produtos contratados por pregão eletrônico. Rev. Adm. Pública, Rio de Janeiro, v. 44, n. 6, p. 1405-1428, Dec. 2010. Disponível em $<$ http://www.scielo.br/scielo.php?script=sci_arttext\&pid=S0034-

$76122010000600007 \& \operatorname{lng}=$ en\&nrm=iso $>$. Acesso em: 15 jun. 2017.

GENEROSO, Leonardo Augusto. A Participação Exclusiva de Microempresas e Empresas de Pequeno Porte nos Pregões Eletrônicos do CEFET/MG. Pedro Leopoldo, 2010. Dissertação (Mestrado em Administração), Faculdades Integradas de Pedro Leopoldo. Disponível em: <

http://www.fpl.edu.br/2013/media/pdfs/mestrado/dissertacoes_2010/dissertacao_leonar do_augusto_generoso_2010.pdf $>$. Acesso em: 13 jul. 2017. 
MARCONI, Marina de Andrade; LAKATOS, Eva Maria. Técnicas de pesquisa. 7.ed. e $2^{\mathrm{a}}$ reimpressão. São Paulo: Atlas, 2009.

PORTER, Michael E. Vantagem competitiva: criando e sustentando um desempenho superior. $5^{\text {a }}$ ed. Rio de Janeiro: Campus, 1992

SERVIÇO BRASILEIRO DE APOIO ÀS MICRO E PEQUENAS EMPRESAS Sebrae. A evolução das microempresas e empresas de pequeno porte de 2009 a 2012. Brasília, 2014. (Série Estudos e Pesquisas).

SEVERINO, Antônio Joaquim. Metodologia do trabalho científico. $23^{\mathrm{a}}$ ed. rev. e atual. Rio de Janeiro: Cortez, 2007.

\section{AGRADECIMENTOS}

Ao Ministério da Saúde que financiou do Curso de Mestrado Profissional em Gestão e Economia da Saúde, à Universidade Federal de Pernambuco que proporcionou o saber e ao Hospital das Clínicas da UFPE que autorizou a pesquisa. 